\title{
The 10th meeting of the Conference of the Parties to the Convention on Biological Diversity-a breakthrough for biodiversity?
}

\author{
PETER HERKENRATH and JeREMy HarRis ON
}

The 1oth meeting of the Conference of the Parties (COP 10; http://www.iisd.ca/biodiv/copio) to the Convention on Biological Diversity (CBD; http://www.cbd.int) took place during 18-29 October 2010 in Nagoya, Japan. It was arguably the most ambitious and difficult meeting since the adoption of the CBD in 1992 and was closely watched by the world's media. COP 10 had before it the task of adopting: a protocol on access and benefit-sharing (ABS) related to genetic resources, a new Strategic Plan for 2011-2020, and an agreement on mobilization of additional financial resources for implementing the Convention. At the preparatory meetings earlier in 2010 developing countries had taken a strong stance, insisting that all three of these issues be adopted as a package. There would be no agreement on the new Strategic Plan without adoption of the ABS Protocol and agreement on a substantial increase in financial resources.

The ABS Protocol has been a tough issue to resolve. A total of nine meetings of the CBD Working Group on ABS had failed to prepare a clean text of the protocol in time for COP 10 (see McNeely, 2010, on the difficulties around the issue of benefit sharing in the context of the CBD). The 2002 World Summit on Sustainable Development's demand for the CBD to develop such a protocol by 2010 was in danger of not being met. This remained so until the final minutes of the final plenary in the early hours of 30 October when, after 2 weeks of negotiations, the package was adopted, helped by the high-level segment attended by 122 environment and other ministers and five Heads of State. The legally-binding Nagoya Protocol on Access to Genetic Resources and the Fair and Equitable Sharing of Benefits Arising from their Utilization is a compromise between the demands of developing and developed countries. The compromise language is ambiguous on some of the key issues, including scope, derivatives, traditional knowledge and compliance, and it therefore remains to be seen whether the Protocol will foster the $\mathrm{CBD}$ objective of fair and equitable sharing of benefits arising from the use of genetic resources. It is nevertheless a significant step forward and it is to be hoped that the new Protocol will quickly come into force.

The negotiations on the post-2010 Strategic Plan proved similarly difficult. In May 2010, on the International Day

Peter Herkenrath and Jeremy Harrison UNEP World Conservation Monitoring Centre, Cambridge, UK

E-mail peter.herkenrath@unep-wcmc.org for Biodiversity, the CBD launched the third edition of Global Biodiversity Outlook (SCBD, 2010). This publication made clear that the target of significantly reducing the rate of biodiversity loss by 2010 had not been met (see Fisher, 2009, for a critical preview of the verdict on the 2010 target). The task for COP 10 was to agree on a new, 2020 target and a range of subtargets. The new target is to 'take effective and urgent action to halt the loss of biodiversity in order to ensure that by 2020 ecosystems are resilient and continue to provide essential services, thereby securing the planet's variety of life, and contributing to human wellbeing and poverty eradication'. The subtargets include, among others, that by 2020 'the rate of loss of all natural habitats...is at least halved and, where feasible, brought close to zero and degradation and fragmentation is significantly reduced'; 'at least $17 \%$ of terrestrial and inland water, and $10 \%$ of coastal and marine areas...are conserved through effectively and equitably managed, ecologically representative and well connected protected area systems and other effective area-based conservation measures, and integrated into the wider landscape and seascapes'; 'the extinction of known threatened species has been prevented and their conservation status...has been improved and sustained'; and 'ecosystem resilience and the contribution of biodiversity to carbon stocks has been enhanced, through conservation and restoration, including restoration of at least $15 \%$ of degraded ecosystems'. The Biodiversity Indicators Partnership, which contributed much of the data supporting the conclusion of non-achievement of the 2010 target (Butchart et al., 2010), was invited to support the development of indicators for the post-2010 targets.

COP 10 agreed on indicators and activities for the CBD Strategy for Resource Mobilization, although, disappointingly, the adoption of targets was deferred to the next COP meeting in 2012. In addition, there were a number of announcements of increased financial resources for implementation of the Convention. In particular the host country, Japan, will make available USD 2 billion over the next 3 years. The COP also adopted guidance to the Convention's financial mechanism, the Global Environment Facility, the fifth replenishment of which had been completed earlier in 2010, with USD 4.35 billion for 2010-2014. However, despite these advances, the feeling remains that the funds available for biodiversity fall significantly short of what is needed. Meanwhile, a draft decision on innovative financial mechanisms such as payments for 
ecosystem services proved too controversial and was not adopted.

The COP adopted a total of 44 further decisions that are less spectacular than the three headline issues but nevertheless important. These include adoption of an updated Global Strategy for Plant Conservation 2011-2020; a Plan of Action on Subnational Governments, Cities and other Local Authorities for Biodiversity; development of a repository for scientific and technical information on the identification of ecologically or biologically significant areas for marine and coastal biodiversity; an appreciation of the Satoyama Initiative that promotes and supports socioecological production landscapes; a de facto moratorium on climate change-related geo-engineering; joint activities with the United Nations Framework Convention on Climate Change and the United Nations Convention to Combat Desertification; application of the precautionary approach to the field release of synthetic life, cell or genome; and the Tkarihwaié:ri (a Mohawk term meaning 'the proper way') Code of Ethical Conduct on Respect for the Cultural and Intellectual Heritage of Indigenous and Local Communities Relevant for the Conservation and Sustainable Use of Biological Diversity.

COP 10 was a huge gathering of over 7,000 negotiators, environmentalists, scientists, NGOs, indigenous peoples, business representatives and youth groups. There were hundreds of side events, a biodiversity fair, numerous receptions and side conferences. Many of the thousands of participants came to Nagoya particularly for sharing their initiatives, experiences and success stories in the fields of conservation, sustainable use, and access and benefitsharing. It was encouraging to see all the regional and local action on biodiversity - a reminder that action on the ground is what the CBD, in setting a global framework, ultimately wants to achieve. But will biodiversity finally become an integral part of decision-making? Will the decisions taken at Nagoya, which are seen by many as not going far enough, help mainstream biodiversity into relevant policies and politics? Can we avoid the nightmare scenario of the virtual biodiversity world of 2030 drawn by Adams (2010)?

We take some encouraging signs from COP 10. Firstly, two groups were particularly visible at Nagoya, business and indigenous peoples, and both have an important role to play in biodiversity conservation. The World Business Council for Sustainable Development showed a particularly strong commitment to support the Convention's implementation. Indigenous peoples' organizations stressed the link between achieving the CBD's objectives and indigenous on-the-ground action for biodiversity. Secondly, links between the biodiversity and the development agendas are stronger than before, with development agencies, banks and policy institutions adopting a declaration for the mainstreaming of the biodiversity agenda into development plans in the margins of the COP. Thirdly, conservation science is likely to become more policy-relevant with the imminent establishment of the Intergovernmental SciencePolicy Platform on Biodiversity and Ecosystem Services (IPBES), which COP 10 welcomed. Finally, if the ABS Protocol manages to curb biopiracy and promote benefitsharing then developing countries, which hold the vast majority of biodiversity, will become much stronger advocates for biodiversity conservation.

The failure of governments to agree strategies to tackle climate change in Copenhagen in 2009 was in the back of many people's minds in the run-up to Nagoya. Therefore the fact that governments have agreed a package of new deals on biodiversity at COP 10 is itself a message of hope, greeted by palpable relief as negotiations were concluded in the small hours of 30 October. Of course, unless the great words in Nagoya are translated into action then this will have been just another very expensive paper exercise. However, the global roadmap-although not as ambitious as hoped for by many-has been set and it resonates far more strongly this time. The first results of the new commitments will hopefully be visible at COP 11 in October 2012 in India. It remains to be seen whether biodiversity will by then have managed to find a permanent place on the political agenda.

\section{References}

A dams, W.M. (2010) Conservation plc. Oryx, 44, 482-484. Butchart, S.H.M., Walpole, M., Collen, B., van Strien, A., Scharlemann, J.P.W., Almond, R.E.A. et al. (2010) Global biodiversity: indicators of recent declines. Science, 328, 1164-1168.

Fisher, M. (2009) 2010 and all that-looking forward to biodiversity conservation in 2011 and beyond. Oryx, 43, 449-450.

MCNeELy, J.A. (2010) Sharing the benefits of biodiversity: some perspectives from the recent history of conservation. Oryx, 44, $480-481$.

SCBD (Secretariat of the Convention on Biological Diversity) (2010) Global Biodiversity Outlook 3. SCBD, Montreal, Canada. 